\title{
Coronary heart disease: prevalence and dietary sugars in Scotland
}

\author{
C Bolton-Smith, M Woodward
}

\begin{abstract}
Study objective - The aim was to investigate the effects of dietary intakes of different types of sugars (extrinsic, intrinsic, and lactose) and the dietary fat to sugar ratio on prevalent coronary heart disease (CHD).
\end{abstract}

Design - This was a baseline cross sectional survey of CHD risk factors.

Setting - Twenty two Scottish health districts were surveyed between 1984 and 1986.

Participants - A total of 10359 men and women aged 40-59 years were screened as part of the Scottish Heart Health Study, and $a$ further 1267 men and women aged 25-39 and 60-64 years were screened as part of the Scottish MONICA (monitoring trends and determinants in cardiovascular disease) Study. The response rates were $74 \%$ and $64 \%$ respectively.

Methods - Subjects completed a questionnaire which included sociodemographic, health, and food frequency information. Medical history, response to the Rose chest pain questionnaire, and results of a 12 lead ECG recording were used to categorise subjects into $\mathrm{CHD}$ diagnosed, previously CHD undiagnosed, or no CHD groups. The $\chi^{2}$ statistic was used to determine whether the CHD groups differed in their sugar consumption, and multiple logistic regression analysis, with adjustment for other potential coronary risk factors, was used to calculate odds ratios for prevalent CHD by intake fifths of dietary sugars.

Main results - Men, but not women, differed in their sugar consumption by CHD group. The odds ratios showed a tendency for a $U$ shaped relationship for extrinsic sugar intake with CHD prevalence, but no significant effect of the fat to sugar ratio (possible marker of obesity) on CHD was seen.

Conclusions - The results suggest that neither extrinsic sugar, intrinsic sugar, nor the fat to sugar ratio are significant independent predictors of prevalent CHD in the Scottish population, when the other major risk factors such as cigarette smoking, blood cholesterol concentration, and antioxidant vitamins intake are accounted for. These new data for different sugar types agree with the consensus view that total sugar intake is not a major marker of coronary heart disease.

Correspondence to: Dr C Bolton-Smith.

Accepted for publication October 1993
Sugar intake per se has not been indicated in the aetiology of chronic disease other than dental caries. The cariogenicity of sugars has been attributed primarily to extrinsic sugar, ${ }^{1}$ although meal frequency, cloyiness of food, and mouth retention time (which may be higher for complex carbohydrates) are of equal importance to cariogenicity, as is the relative intracellular or extracellular source of the sugars. Results from the cross sectional Scottish Heart Health Study suggested a possible lower prevalence of CHD in men with higher rather than lower total sugar intakes. ${ }^{2}$ Since a low dietary fat to extrinsic sugar ratio has been related to a lower prevalence of overweight and obesity, independent of total energy intake, and there may be plausible energy related bases for this, ${ }^{3}$ it was considered pertinent to investigate further the relative roles of different sugar types to CHD prevalence in the Scottish population.

To investigate the true effect of dietary sugars on CHD prevalence, it is necessary to distinguish the dietary effects of having been diagnosed with heart disease from the initial dietary pattern which may give rise to the disease. In cross sectional studies this is best done by analysing those people with diagnosed CHD separately from those people who consider themselves healthy, but who on examination do have symptoms of $\mathrm{CHD}^{24}$ In this report, multiple logistic regression analysis is used to examine the odds of having either diagnosed or previously undiagnosed CHD according to the amount of different sugars in the diet. Adjustment is made for the confounding factors such as relative weight, age, blood cholesterol, blood pressure, smoking, and dietary antioxidant vitamin intakes.

\section{Subjects and methods}

For the Scottish Heart Health Study, subjects were randomly selected in each of four age-sex groups from the lists of 10 general practitioners in each of 22 Scottish health districts to give a wide spread of CHD mortality. The selected patients were sent a letter, co-signed by their GP, with a questionnaire to complete and an invitation to attend a clinic for medical examination, as reported previously. ${ }^{5}$ A total of 10359 men and women aged 40-59 years were recruited into the Scottish Heart Health Study (response rate $74 \%$ ). Over the same period (1984-86) a further 1267 men and women aged 25-39 and 60-64 years were recruited using identical methods from two areas, Edinburgh and north Glasgow, as part of the international collaborative study of trends 
and determinants of cardiovascular disease (MONICA). ${ }^{6}$

Dietary information was obtained by food frequency questionnaire, ${ }^{7}$ CHD status by a medical history and the Rose chest pain questionnaire with additional evidence from a 12 lead ECG recording. The ECG, blood pressure, weight, and height were recorded at a clinic attendance where a non-fasted venous blood sample was also taken for various biochemical analyses, including blood cholesterol concentrations and serum cotinine as an independent marker of smoking status. ${ }^{8}$ Self reported smoking history was recorded using the WHO smoking questionnaire. ${ }^{9}$

Nutrient intakes were calculated from the food frequency questionnaire using standard portion sizes and the UK food composition tables in a computerised form. Validation studies in this Scottish population have been reported. ${ }^{1011}$ Total dietary sugars were assigned to intrinsic, extrinsic, or milk sugar categories, based on Ministry of Agriculture, Food and Fisheries guidelines. Intrinsic sugar was that present naturally in whole fresh fruits, vegetables, and grains, plus $50 \%$ of the analysed sugars present in cooked, dried, or processed fruits. Extrinsic sugar (non-milk) was that sugar not naturally occurring within the intracellular structure of foods, plus $50 \%$ of the sugar in cooked, dried, or processed fruits. Lactose was sugar derived from milk, regardless of its location (that is, including lactose in chocolate, puddings, etc).

Study subjects were categorised into control, undiagnosed $\mathrm{CHD}$, or diagnosed $\mathrm{CHD}$ groups $^{2}$ according to their response to the medical history and the Rose angina questionnaires, ${ }^{12}$ and on the basis of the ECG recording. Controls were those without any evidence of $\mathrm{CHD}$, and without a history of taking drugs for cardiovascular disease or hypertension. Undiagnosed CHD subjects were those who had no previous history of $\mathrm{CHD}$, but who either responded positively to the angina questionnaire or exhibited the $\mathrm{Q} / \mathrm{QS}$ pattern or $\mathrm{ST}$-segment and $\mathrm{T}$-wave changes on their ECG. ${ }^{13}$ The diagnosed CHD group were those who reported a previous medical diagnosis of myocardial infarction or angina. Subjects taking cardiovascular or hypertensive medication but with no other indication of CHD were omitted from further analysis.

\section{STATISTICAL METHODS}

Mean (SD) values are reported. Analysis of variance was performed on the appropriately transformed data to improve the normality of distributions: these were square root transformations for $\mathrm{g} /$ day intrinsic and extrinsic sugars; arcsine square root transformations for the $\%$ energy values of intrinsic, extrinsic, and lactose sugars; and logarithmic transformations for the fat to sugar ratios.

The $\chi^{2}$ tests were used to assess the differences in distribution of CHD status by fifths of sugar intakes within sexes, and multiple logistic regression for determining odds ratios for the prevalence of CHD relative to the lowest fifth of intake for each sugar variable. Adjustment was made for age, total serum cholesterol, diastolic blood pressure, dietary antioxidant vitamins (vitamins $\mathrm{C}$ and $\mathrm{E}$, and $\beta$ carotene), smoking, $\mathrm{g}$ /day of alcohol, weight, and height. Any additional effect of social class was investigated by including this as a covariate in one model, and total energy intake was also adjusted for when the odds ratios were determined on the $\mathrm{g} /$ day intake data.

\section{Results}

The response rates for the Scottish Heart Health and the MONICA studies were $74 \%$ and $64 \%$ respectively. Dietary data were obtained from an average of $95 \%$ of the total 5768 men and 5858 women who completed the studies.

Table 1 shows the number of men and women categorised into each of the CHD groups, and the mean dietary intakes of sugars and fat to sugar ratios in the different CHD groups. No significant differences were observed for women, while for men the percentage of energy from intrinsic sugar and lactose tended to be lower in the undiagnosed group, and the fat to sugar ratios were higher in both the diagnosed and undiagnosed groups than in the controls.

Differences between the proportion of diagnosed and undiagnosed people in each fifth of sugar intakes were found to be significant for men, with respect to extrinsic sugar (g/day and $\%$ energy), lactose ( $\mathrm{g} /$ day), intrinsic sugar ( $\%$ energy), and the fat to extrinsic sugar ratio, but not for women (results not shown). This meant that the undiagnosed and diagnosed groups

Table 1 Mean (SD) daily intake of sugars by coronary heart disease (CHD) group

\begin{tabular}{|c|c|c|c|c|c|c|c|}
\hline & \multicolumn{3}{|l|}{ Men } & \multirow[b]{2}{*}{$p$} & \multicolumn{3}{|l|}{ Women } \\
\hline & Control & Undiagnosed & Diagnosed & & Control & Undiagnosed & Diagnosed \\
\hline No & 4340 & 772 & 411 & & 4283 & 891 & 263 \\
\hline $\begin{array}{l}\text { Intrinsic sugar: } \\
\text { g/day } \\
\% \text { energy }\end{array}$ & $\begin{array}{c}12.4(7 \cdot 7) \\
2.06(1 \cdot 40)\end{array}$ & $\begin{array}{cl}11.6 & (7.2) \\
1.89 & (1.32)\end{array}$ & $\begin{array}{c}11.6(7.2) \\
2 \cdot 19(1.51)\end{array}$ & $\begin{array}{l}* * \\
* * *\end{array}$ & $\begin{array}{cl}14.8 & (7.7) \\
3.31 & (1.92)\end{array}$ & $\begin{array}{cl}15.0 & (8.0) \\
3.31 & (1.97)\end{array}$ & $\begin{array}{c}14 \cdot 1(7.9) \\
3 \cdot 15(1.81)\end{array}$ \\
\hline $\begin{array}{l}\text { Extrinsic sugar: } \\
\text { g/day } \\
\% \text { energy }\end{array}$ & $\begin{array}{ll}73 \cdot 2 & (45 \cdot 0) \\
11 \cdot 2 & (5 \cdot 4)\end{array}$ & $\begin{array}{ll}77 \cdot 8 & (51 \cdot 2) \\
11 \cdot 4 & (6 \cdot 1)\end{array}$ & $\begin{array}{ll}64 \cdot 8 & (49 \cdot 1) \\
10 \cdot 5 & (6 \cdot 1)\end{array}$ & $\begin{array}{l}* * * \\
* *\end{array}$ & $\begin{array}{c}41 \cdot 6(30 \cdot 8) \\
8 \cdot 55(5 \cdot 1)\end{array}$ & $\begin{array}{c}42 \cdot 8(32 \cdot 2) \\
8 \cdot 63(5 \cdot 39)\end{array}$ & $\begin{array}{r}43.6(35.9) \\
9 \cdot 10(5.96)\end{array}$ \\
\hline $\begin{array}{l}\text { Lactose: } \\
\text { g/day } \\
\% \text { energy }\end{array}$ & $\begin{array}{c}20 \cdot 6(7 \cdot 6) \\
3.34(1 \cdot 28)\end{array}$ & $\begin{array}{cl}20 \cdot 5 & (8 \cdot 1) \\
3 \cdot 25 & (1 \cdot 34)\end{array}$ & $\begin{array}{c}19.6(7.9) \\
3.53(1.48)\end{array}$ & $*$ & $\begin{array}{c}19 \cdot 1(7 \cdot 4) \\
4 \cdot 14(1 \cdot 58)\end{array}$ & $\begin{array}{l}19.0(7.4) \\
4.05(1.55)\end{array}$ & $\begin{array}{c}18 \cdot 3(7 \cdot 8) \\
4 \cdot 02(1 \cdot 73)\end{array}$ \\
\hline $\begin{array}{l}\text { Fat: total sugar: } \\
\% \text { energy } \\
\text { Fat: extrinsic sugar: }\end{array}$ & $2.38(1 \cdot 16)$ & $2.52(1.51)$ & $2.57(1.41)$ & $*$ & $2.79(1.30)$ & $2.85(1.34)$ & $3.03(2.54)$ \\
\hline$\%$ energy & $4.28(3.40)$ & $4.69(4.65)$ & $5 \cdot 10(4 \cdot 65)$ & $* *$ & $6.45(5.31)$ & $6 \cdot 72(6 \cdot 44)$ & $4 \cdot 31(6 \cdot 84)$ \\
\hline
\end{tabular}

Significant difference between male $\mathrm{CHD}$ groups by analysis of variance on appropriately transformed data (see statistical methods); ${ }^{*} p<0.05,{ }^{* *} p<0 \cdot 01,{ }^{* * *} p<0 \cdot 001$. No significant differences for women. 
Table 2 Distribution of coronary heart disease (CHD) groups (\%*) by intake fifths of different sugars

\begin{tabular}{|c|c|c|c|c|c|c|c|c|c|c|c|}
\hline & \multicolumn{5}{|c|}{ Men (fifths) } & \multirow[b]{2}{*}{$p$} & \multicolumn{5}{|c|}{ Women (fifths) } \\
\hline & 1 & 2 & 3 & 4 & 5 & & 1 & 2 & 3 & 4 & 5 \\
\hline \multicolumn{12}{|l|}{ Intrinsic sugar: } \\
\hline Control & 76 & 79 & 78 & 81 & 80 & & 78 & 79 & 81 & 77 & 79 \\
\hline Undiagnosed CHD & 16 & 15 & 14 & 12 & 13 & * & 17 & 17 & 14 & 18 & 16 \\
\hline Diagnosed CHD & & & 8 & 7 & 9 & & 6 & 4 & 5 & 5 & 5 \\
\hline \multicolumn{12}{|l|}{ Extrinsic sugar: } \\
\hline Control & 75 & 80 & 81 & 82 & 76 & & 77 & 81 & 81 & 79 & 78 \\
\hline Undiagnosed CHD & 15 & 13 & 13 & 12 & 16 & $* * *$ & 18 & 15 & 16 & 17 & 16 \\
\hline Diagnosed CHD & 11 & 7 & 6 & 6 & 8 & & 5 & 5 & 4 & 4 & 6 \\
\hline \multicolumn{12}{|l|}{ Lactose: } \\
\hline Control & 77 & 79 & 82 & 80 & 77 & & 76 & 79 & 79 & 79 & 80 \\
\hline Undiagnosed CHD & 16 & 14 & 12 & 13 & 14 & * & 18 & 16 & 16 & 17 & 15 \\
\hline Diagnosed CHD & 6 & 7 & 6 & 8 & 9 & & 5 & 5 & 5 & 4 & 5 \\
\hline \multicolumn{12}{|l|}{ Fat: total sugar: } \\
\hline Control & 79 & 79 & 81 & 78 & 76 & & 79 & 79 & 81 & 79 & 78 \\
\hline Undiagnosed CHD & 15 & 13 & 13 & 15 & 15 & * & 16 & 15 & 18 & 16 & 17 \\
\hline Diagnosed CHD & 7 & 8 & 6 & 7 & 9 & & 5 & 4 & 5 & 4 & 6 \\
\hline
\end{tabular}

* Percentage values were rounded to nearest whole number

Significance level $\left(\chi^{2}\right)$ for men: ${ }^{*} p<0.05,{ }^{* *} p<0.01,{ }^{* * *} p<0.001$. No significant differences for women. fifths of extrinsic sugar intake, where the risk of diagnosed CHD is lower by $34 \%$ (CI 4,55 ) and the risk of undiagnosed $\mathrm{CHD}$ is lower by $28 \%$ (CI 5,46). Although the ORs do differ significantly between the fifths for undiagnosed CHD, there is no evidence of a doseresponse effect for extrinsic sugar or for any of the other sugar variables examined.

The situation differs only slightly for women (table 4), in whom the risk of prevalent CHD (diagnosed or undiagnosed) is significantly lower in the middle fifth of intrinsic sugar intake, and shows a non-significant tendency to be lower in the middle fifths of extrinsic sugar intake. A slight, although again not significant, dose-response effect is seen for the ORs by fifths of the fat to sugar ratio. Significantly lower prevalent CHD occurs in the upper two fifths, with the maximum effect being a $24 \%$ (CI 2,41 ) reduction from the highest fat to sugar intake group compared with the lowest.

The results were unchanged when the sugar variables were expressed as a percentage of total energy intake rather than as $\mathrm{g} /$ day. Further adjustment for occupational social class had no significant effect on the results either. women no differences were observed, even when the two CHD groups were combined (data not shown).

The odds ratios (OR) for prevalent CHD by fifths of sugar intakes, adjusted for other potential coronary risk factors, are shown in tables 3 and 4. The diagnosed and undiagnosed groups are considered separately for men, but are pooled for women. For men (table 3), only two ORs are significantly different relative to the lowest fifth of intake (characterised by $95 \%$ confidence intervals (CI) which do not span 1). These are middle

\section{Discussion}

Similar analyses of such cross-sectional data have previously proved valuable for identifying the antioxidant vitamins as important dietary factors for predicting the prevalence of CHD in this Scottish population. ${ }^{4}$ Thus, the number of CHD cases in this analysis provides sufficient power to detect biologically significant effects of individual nutrients. However,

Table 3 Male odds ratios (OR) (95\% confidence intervals (CI)) for prevalent diagnosed and undiagnosed coronary heart disease (CHD) by intake fifths of dietary sugars

\begin{tabular}{|c|c|c|c|c|c|c|c|c|c|}
\hline & \multicolumn{9}{|c|}{ Fifths } \\
\hline & $\stackrel{I}{O R}$ & $\stackrel{2}{O R}$ & $(C I)$ & $\stackrel{3}{O R}$ & $(C I)$ & $\stackrel{4}{O R}$ & $(C I)$ & $\begin{array}{l}5 \\
O R\end{array}$ & $(C I)$ \\
\hline \multicolumn{10}{|l|}{ Intrinsic sugar: } \\
\hline Diagnosed CHD & $1 \cdot 0$ & 0.75 & $(0 \cdot 50,1 \cdot 13)$ & 1.07 & $(0.73,1.58)$ & 0.92 & $(0.61,1 \cdot 40)$ & 0.98 & $(0 \cdot 61,1 \cdot 57)$ \\
\hline $\begin{array}{l}\text { Undiagnosed CHD } \\
\text { Extrinsic sugar: }\end{array}$ & $1 \cdot 0$ & $1 \cdot 00$ & $(0 \cdot 77,1 \cdot 30)$ & 1.02 & $(0 \cdot 77,1 \cdot 35)$ & $0 \cdot 85$ & $(0 \cdot 62,1 \cdot 26)$ & $1 \cdot 18$ & $(0.83,1.68)$ \\
\hline Diagnosed CHD & 1.0 & 0.78 & $(0 \cdot 55,1 \cdot 11)$ & 0.66 & $(0 \cdot 45,0 \cdot 96)$ & $0 \cdot 75$ & $(0.51,1 \cdot 10)$ & 0.97 & $(0.6$ \\
\hline Undiagnosed CHD & 1.0 & 0.96 & $(0.71,1.23)$ & 0.77 & $(0.58,1 \cdot 02)$ & 0.72 & $(0 \cdot 54,0.95)$ & 1.03 & $(0 \cdot 78,1 \cdot 37)^{*}$ \\
\hline \multicolumn{10}{|l|}{ Lactose: } \\
\hline Diagnosed CHD & $1 \cdot 0$ & 0.99 & $(0 \cdot 67,1 \cdot 46)$ & 0.84 & $(0 \cdot 56,1 \cdot 26)$ & 1.05 & $(0.71,1.55)$ & $1 \cdot 20$ & $(0 \cdot 82,1 \cdot 78)$ \\
\hline Undiagnosed CHD & $1 \cdot 0$ & 0.97 & $(0 \cdot 75,1 \cdot 26)$ & 0.83 & $(0.63,1.09)$ & 0.95 & $(0 \cdot 72,1 \cdot 25)$ & 1.22 & $(0.91,1.62)$ \\
\hline \multicolumn{10}{|c|}{ Fat: total sugars ( $\%$ energy) } \\
\hline $\begin{array}{l}\text { Diagnosed CHD } \\
\text { Undiagnosed CHD }\end{array}$ & $\begin{array}{l}1 \cdot 0 \\
1 \cdot 0\end{array}$ & $\begin{array}{l}1.23 \\
0.79\end{array}$ & $\begin{array}{l}(0 \cdot 84,1 \cdot 78) \\
(0 \cdot 61,1 \cdot 04)\end{array}$ & $\begin{array}{l}0 \cdot 84 \\
0.84\end{array}$ & $\begin{array}{l}(0 \cdot 56,1 \cdot 27) \\
(0 \cdot 64,1 \cdot 11)\end{array}$ & $\begin{array}{l}0.74 \\
0.98\end{array}$ & $\begin{array}{l}(0.49,1 \cdot 11) \\
(0.75,1.29)\end{array}$ & $\begin{array}{l}1.01 \\
0.92\end{array}$ & $\begin{array}{l}(0 \cdot 68,1 \cdot 48) \\
(0 \cdot 69,1 \cdot 21)\end{array}$ \\
\hline
\end{tabular}

OR relative to the lowest intake fifth. Bold type identifies ORs which differ significantly from $1 \cdot 0$, and italic type identifies ORs which border on a significant difference from 1.0 .

* Indicates a significant difference $(p<0.05)$ in the adjusted prevalences of CHD between intake fifths for that sugar variable.

Table 4 Odds ratios (OR) (95\% confidence intervals (CI)) for prevalent coronary heart disease (CHD) (diagnosed and undiagnosed) in women by intake fifths of dietary sugars

\begin{tabular}{|c|c|c|c|c|c|c|c|c|c|}
\hline & \multicolumn{9}{|c|}{ Fifths } \\
\hline & $\stackrel{1}{O R}$ & $\stackrel{2}{O R}$ & $(C I)$ & $\begin{array}{l}3 \\
O R\end{array}$ & $(C I)$ & $\stackrel{4}{O R}$ & $(C I)$ & $\begin{array}{l}5 \\
O R\end{array}$ & $(C I)$ \\
\hline $\begin{array}{l}\text { Intrinsic sugar } \\
\text { Extrinsic sugar } \\
\text { Lactose } \\
\text { Fat: total sugars ( } \% \text { energy) }\end{array}$ & $\begin{array}{l}1.0 \\
1.0 \\
1 \cdot 0 \\
1.0\end{array}$ & $\begin{array}{l}0.90 \\
0.86 \\
0.90 \\
0.81\end{array}$ & $\begin{array}{l}(0 \cdot 70,1 \cdot 17) \\
(0 \cdot 66,1 \cdot 10) \\
(0 \cdot 71,1 \cdot 16) \\
(0 \cdot 63,1 \cdot 03)\end{array}$ & $\begin{array}{l}0 \cdot 72 \\
0 \cdot 82 \\
0 \cdot 99 \\
0 \cdot 87\end{array}$ & $\begin{array}{l}(0 \cdot 55,0 \cdot 95) \\
(0 \cdot 63,1 \cdot 06) \\
(0 \cdot 78,1 \cdot 27) \\
(0 \cdot 68,1 \cdot 12)\end{array}$ & $\begin{array}{l}1.06 \\
0.94 \\
0.96 \\
0.77\end{array}$ & $\begin{array}{l}(0 \cdot 79,1 \cdot 41) \\
(0 \cdot 73,1 \cdot 21) \\
(0 \cdot 75,1 \cdot 23) \\
(0 \cdot 60,0 \cdot 99)\end{array}$ & $\begin{array}{l}0.91 \\
1 \cdot 17 \\
0.91 \\
0 \cdot 76\end{array}$ & $\begin{array}{l}(0.65,1 \cdot 28)^{*} \\
(0.91,1 \cdot 51)^{*} \\
(0 \cdot 70,1 \cdot 17) \\
(0 \cdot 59,0 \cdot 98)\end{array}$ \\
\hline
\end{tabular}

OR relative to the lowest intake fifth. Bold type identifies ORs which differ significantly from $1 \cdot 0$, and italic type identifies ORs which border on a significant difference from $1 \cdot 0$.

* Indicates a significant difference $(p<0.05)$ in the adjusted prevalences of CHD between intake fifths for that sugar variable. 
these results do not suggest any significant role for the different dietary sugars in the prediction of CHD risk, since there is a noticeable lack of any dose-response effect. A dose-response effect is the best indicator of a true cause and effect relationship in the absence of any biologically plausible reason for a $U$ shaped relationship (such as occurs for alcohol and CHD). While it is possible that the lowest and highest intake groups may be at higher risk of $\mathrm{CHD}$ as a result of other factors that have not been adequately adjusted for in the logistic regression models, there is no evidence to suggest that this is so.

These results seem to support the already large body of evidence which suggests that dietary intake of sugars has no specific bearing on CHD risk. ${ }^{1}$ They extend the existing knowledge regarding sugar intake and $\mathrm{CHD}$ by clarifying that extrinsic sugar intake cannot be differentiated from the effects of intrinsic sugar or lactose. Furthermore, no coronary benefit seems to accrue from a relatively low fat and high sugar diet, which is associated with lower relative weight and lower prevalence of obesity. This seems to confirm the current view that obesity per se is not a major risk factor for CHD, and that the other risk factors, such as cigarette smoking and antioxidant vitamin intake (which were fully adjusted for in the analysis reported here), are more important predictors of CHD.

The Scottish Heart Health and MONICA studies were funded primarily by the Scottish Office Home and Health Department and $C B-S$ is grateful for financial support from the Sugar
Bureau. The opinions expressed are those of the authors, and not necessarily those of the funding bodies.

1 Committee of Medical Aspects of Food Policy (COMA). Dietary sugars and human disease. London: HMSO, 1989.

Bolton-Smith C, Woodward M, Tunstall-Pedoe H. Dietary intake by food frequency questionnaire and odds ratios intake by food frequency questionnaire and odds ratios for coronary heart disease.

3 Flatt JP. The difference in storage capacities for carbohydrate and for fat, and its implications in the regulation of body weight. Ann NY Acad Sci 1987;499:104-23.

4 Bolton-Smith C, Woodward M, Tunstall-Pedoe H. Dietary intake by food frequency questionnaire and odds ratios for coronary heart disease. II The antioxidant vitamins and fibre. Eur f Clin Nutr 1992;46:85-93.

5 Smith WCS, Tunstall-Pedoe $\mathrm{H}$, Crombie IK, Tavendale R. Concomitants of excess coronary deaths: major risk factor and lifestyle findings from 10,359 men and women in the Scottish Heart Health Study. Scot Med $f$ 1989;34:550-5.

6 Tunstall-Pedoe $\mathrm{H}$, for the WHO MONICA Project Principal Investigators. The World Health Organisation pal Investigators. The World Health Organisation MONICA project (monitoring trends and determinants in cardiovascular disease): a major internation.

7 Bolton-Smith C, Smith WCS, Woodward M, TunstallPedoe $H$. Nutrient intakes of different social-class groups: results from the Scottish Heart Health Study (SHHS). B f Nutr 1991;65:321-35.

8 Woodward M, Tunstall-Pedoe $H$. Biochemical evidence of persistent heavy smoking after a coronary diagnosis despite self-reported reduction: analysis from the Scottish Heart Health Study. Eur Heart f 1992;13:160-5.

9 Rose GA, Blackburn H, Gillum RF, Prineas RJ. Cardiovascular survey methods. Geneva: World Health Organisation, 1982 .

10 Bolton-Smith C, Milne AC. Food frequency questionnaire versus weighed intake data in Scottish men. Proc Nutr Soc 1991;50:35A.

11 Bolton-Smith C, Casey CE, Gey KF, Smith WCS, Tunstall-Pedoe $\mathrm{H}$. Antioxidant vitamin intakes assessed using a food frequency questionnaire: correlation with bio-
chemical status in smokers and non-smokers. $\mathrm{Br} 7 \mathrm{Nutr}$ chemical status

12 Rose GA, McCartney P, Reid DD. Self administration of a questionnaire on chest pain and intermittent claudication. Br F Prev Soc Med 1977;31:42-8.

13 Prineas RJ, Crow RS, Blackburn H. The Minnesota code manual of electrocardiographic findings. Bristol: John Wright, 1982. 